\title{
Integrated Assessment of Swiss GHG Mitigation Policies After 2012
}

\author{
Coupling the Residential Sector
}

\author{
André Sceia - Juan-Carlos Altamirano-Cabrera • \\ Laurent Drouet • Thorsten F. Schulz • Marc Vielle
}

Received: 7 January 2009 / Accepted: 28 July 2011 / Published online: 18 August 2011

(C) Springer Science+Business Media B.V. 2011

\begin{abstract}
The residential sector presents a great potential for greenhouse gases (GHG) mitigation. We perform an integrated assessment of different mitigation policies for Switzerland focusing on the residential sector. We analyze the case of pure incentive taxes and technical regulations. For our analysis, we have coupled a general equilibrium model with a Swiss residential energy model. We find that a progressive GHG tax of more than $200 \mathrm{USD} 2000 / \mathrm{tCO}_{2}$ eq is necessary to reach a target of $50 \%$ reduction of GHG emissions in 2050. Finally, we also find that efficiency-based technical regulations provide limited additional abatement incentives.
\end{abstract}

A. Sceia $(\bowtie) \cdot$ J.-C. Altamirano-Cabrera $\cdot$ L. Drouet

Research Lab on the Economics and Management of the Environment (REME), Swiss Federal Institute of Technology at Lausanne (EPFL),

1015 Lausanne, Switzerland

e-mail: andre.sceia@gmail.com

J.-C. Altamirano-Cabrera

e-mail: jcarlos.altamirano@gmail.com

L. Drouet

e-mail:1drouet@gmail.com

T. F. Schulz

Energy Economics Group, Paul Scherrer Institute (PSI),

5232 Villigen, Switzerland

e-mail: t.f.s@gmx.net

M. Vielle

REME-EPFL and Toulouse School of Economics

(LERNA), Manufacture des Tabacs, 21 Allée de Brienne,

31000 Toulouse Cedex, France

e-mail: marc.vielle@epfl.ch
Keywords Swiss residential sector • Climate policy • Top-down and bottom-up models

\section{Introduction}

In many industrialized countries, the residential sector accounts for an important and increasing share of greenhouse gases (GHG) emissions. For instance, in 2005, the Swiss residential sector was responsible for $22.3 \%$ of total GHG emissions. These emissions are mainly due to the combustion of light fuel oil used for room and water heating. When we add the emissions from transport to those of the residential sector, they represent more than half of the total GHG emissions, a huge proportion when we consider that industry was only responsible for $21.6 \%$. This Swiss specificity is mainly due to two factors. First, the major part of high energy goods are imported into Switzerland; indeed, the Swiss economy is more based on services than on heavy industry. Secondly, electricity is produced at almost $95 \%$ with hydro- and nuclear powerplants. As a result, the residential sector presents some of the more interesting low hanging fruits with regard to GHG abatement. Energy saving investments like insulation will become increasingly profitable if energy prices keep on rising. Moreover, efficient technologies for space and water heating, e.g., heat pumps and solar, are available today for both houses and apartment buildings. With that in mind, it makes perfect sense for Swiss policy makers to pay a special attention to the residential sectors when devising climate policies.

The current Swiss climate policy will comply with the objectives fixed in the Kyoto Protocol, though they are not sufficient to meet the objectives of the current 
$\mathrm{CO}_{2}$ Law that prescribes a further emissions reduction. The law provides for a reduction of 2.9 million tons of $\mathrm{CO}_{2}$. According to current estimates, there will be excess emissions of 0.5 million tons of $\mathrm{CO}_{2}$ with respect to the objective fixed by the law. Considering the post2012 climate policy, in February 2008, the Swiss Federal Council decided to launch a revision of the $\mathrm{CO}_{2} \mathrm{Law}$. It decided to follow similar targets as the European Union, i.e., at least $20 \%$ reduction of GHG by 2020 and $50 \%$ by 2050 . A consultation procedure on this revision was launched in December 2008 in order to compare various envisaged instruments: a pure incentive tax (the revenue of which would be redistributed to households), a tax financing national or international abatement, or adaptation measures as well as technical regulations.

The objective of this paper is to assess some of the instruments envisaged for the revision of the Swiss $\mathrm{CO}_{2}$ Law. We focus on the residential sector given its potential when it comes to GHG abatement. To attain our objective, we devise a coupled model, combining a global economic model (GEMINI-E3, see Section 2.1) with a Swiss residential energy use model (MARKALCHRES, see Section 2.2). The benefit of coupling a top-down computable general equilibrium (CGE) with a bottom-up energy use models is twofold. On the one hand, it allows us to estimate the consequences of national policies on the Swiss economy and more specifically on the Swiss residential sector. On the other hand, the coupled model allows to test policies targeting energy use in the Swiss residential sector with a very detailed representation of the energy technologies both used and available in that sector and to assess the impact of those policies on the overall economy.

The coupling between top-down and bottom-up models has already been explored in the literature (see, among other, $[4,8,17,18,22,24,30])$. We have nevertheless followed an approach relatively different from those used by these authors. In [17, 22, 24], the coupling has been mainly carried out in the calibration phase of the modeling; bottom-up models were used to calibrate some of the parameters in the top-down models. Different from them, we have linked the models in the simulation phase. In $[4,30]$, technology details have been directly incorporated into a CGE model. In contrast, we have worked with existing bottom-up and top-down models and tried to keep them as close as possible from their original formulation. Therefore, both models have been kept separate, while linking them with a coupling module. In [18], a reduced CGE model is incorporated in a bottom-up model. In contrast, we tried to keep our CGE as complete as possible, allowing for a more complete and realistic interpreta- tion of the results for the current consultation procedure on the future of the Swiss $\mathrm{CO}_{2}$ law. Finally, until now, the only coupling paper specifically targeted to the Swiss residential sector is [8]. They have devised an hybrid model where the residential sector energy consumption is removed from the top-down model and replaced by an exogenous and separate bottom-up model.

This paper aims at further developing the coupling methodology, dynamically integrating the results from the bottom-up model into the top-down model without touching the interactions between the residential sector and the rest of the economy. The coupling procedure we have implemented allows for estimating $\mathrm{CO}_{2}$ or GHG taxes in response to national emission targets. Furthermore, it allows for simulation of technical regulations in the residential sector. Finally, the coupled model allows an integrated analysis of the implications of the policies on the Swiss and the global economy as well as on the Swiss residential sector. From our analysis, we find that in Switzerland, without emissions trading mechanisms, the rapid implementation of a progressive GHG tax reaching more than 200 USD per ton of $\mathrm{CO}_{2}$ equivalent (USD/tCO $\mathrm{tC}_{2}$ eq) would be necessary in order to achieve a GHG abatement of $50 \%$ in 2050 . With such levels of taxation, we also find that technical regulations do not bring additional incentives to abate emissions.

The paper is organized as follows: Section 2 presents both the GEMINI-E3 and MARKAL-CHRES models, Section 3 explains how the baseline scenario of the models has been calibrated, Section 4 presents the coupling procedure and a sensitivity analysis of the coupled model, Section 5 presents the policy scenarios, Section 6 the numerical results, and Section 7 concludes.

\section{Models}

\subsection{GEMINI-E3}

The complete GEMINI-E3 is a dynamic-recursive CGE model that represents the world economy in 28 regions (including Switzerland) and 18 sectors. It incorporates a highly detailed representation of indirect taxation [1]. For this study, we use an aggregated version of the model in six regions, i.e., Switzerland (CHE), European Union, other European and Euroasian countries, Japan, USA, Canada, Australia, and New Zealand and other countries, mainly developing countries. The model is formulated as a mixed complementarity problem, which is solved using GAMS and the PATH solver $[10,11]$. GEMINI-E3 is built on a 
comprehensive energy economy data set, the GTAP-6 database [6], that provides a consistent representation of energy markets in physical units and a detailed social accounting matrix for a large set of countries or regions and bilateral trade flows between them. Moreover, we have completed the data from the GTAP database with information on indirect taxation and government expenditures from the International Energy Agency [1416], the OECD [20, 21], and the International Monetary Fund [13]. For Switzerland, we used data from the 2001 input-output table devised at the Swiss Federal Institute of Technology Zürich [19], which we transformed into the GEMINI-E3 format [23]. All the data on emissions and abatement costs for non- $\mathrm{CO}_{2}$ GHG come from the US Environmental Protection Agency [29]. For a complete description of GEMINI-E3, see [3]. Various versions of the model have been used to analyze the implementation of economic instruments allowing for GHG emissions reductions in a second-best setting [2].

Apart from a comprehensive description of indirect taxation, the specificity of the model is that it simulates all relevant markets: commodities (through relative prices), labor (through wages), as well as domestic and international savings (through rates of interest and exchange rates). Terms of trade (i.e., transfers of real income between countries resulting from variations of relative prices of imports and exports) and "real" exchange rates can also be accurately modeled.

Time periods are linked in the model through endogenous real interest rates, which are determined by the equilibrium between savings and investments. National and regional models are linked by endogenous real exchange rates resulting from constraints on foreign trade deficits or surpluses.

In order to allow the calibration and the coupling of GEMINI-E3 with MARKAL-CHRES, we have replaced the Stone-Geary utility function by a nested constant elasticity of substitution (CES) function. The nesting structure is shown in Fig. 1 . The $\sigma^{x}$ refer to the elasticity parameter of each node. Plain numbers in the figure refer to economic sectors, those in brackets refer to sectors appearing at various levels in the CES function, and numbers in italics are the values of the elasticity parameters. Details about the equations used the residential nest of the CES function are presented in "Appendix." It is important to note that "other" inputs in the residential nest encompass construction costs related to the installation of energyrelated technologies (e.g., insulation and heat pumps) as well as the purchase of energy related equipments such as furnaces. Nevertheless, it does not contain the
Fig. 1 Structure of the households' nested CES utility function $\left(\sigma^{x}\right.$ : elasticity)

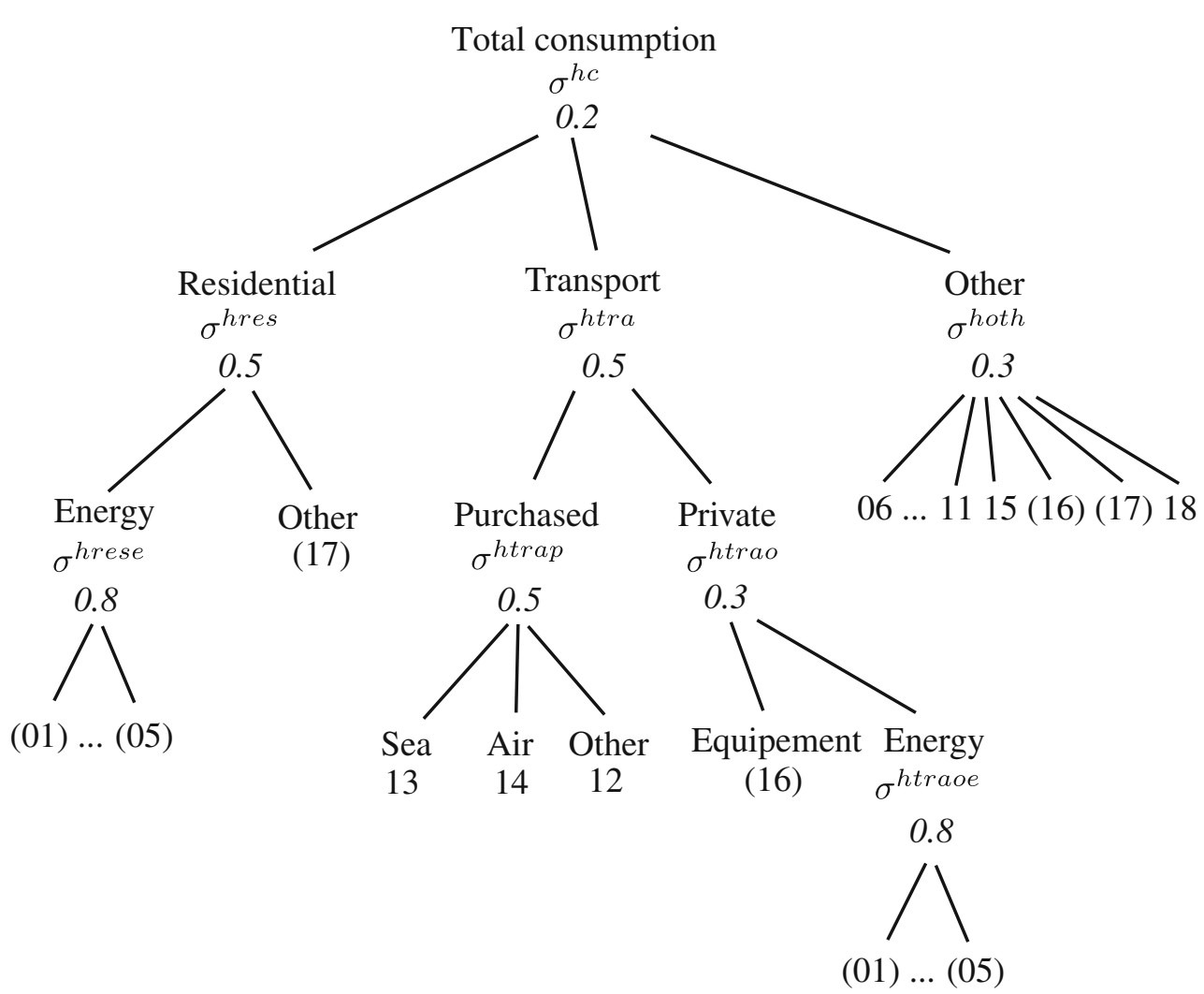


construction of the buildings themselves. Furthermore, for Switzerland, only petroleum products are used as input in the transportation energy nest.

Finally, in order to better match the actual Swiss taxation scheme, we have differentiated excise taxes for heating oil from those of petroleum products used as transportation fuels. In order to do so, we introduced a basic excise tax (ExTax base), fixed at the level of the 2001 residential excise tax, and a supplementary excise $\operatorname{tax}\left(\operatorname{ExTax}_{\text {sup }}\right)$ applied only in the transportation sector. Therefore, in the residential sector, we use a final consumption price equal to $\mathrm{PC}=\left(\mathrm{PB}+\operatorname{ExTax}_{\text {base }}\right) \times$ $(1+\mathrm{vat})$, where $\mathrm{PB}$ is the production price and vat the rate of value added tax. In the transportation sector, we add the supplementary excise, and therefore, $\mathrm{PC}_{\text {trans }}=$ $\mathrm{PC}+\operatorname{ExTax}_{\text {sup }}(1+$ vat $)$. This is equivalent to $\mathrm{PC}_{\text {trans }}=$ $\left(\mathrm{PB}+\operatorname{ExTax}_{\text {base }}+\operatorname{ExTax}_{\text {sup }}\right) \times(1+$ vat $)$.

\subsection{MARKAL-CHRES}

The MARKAL-CHRES is an energy model describing the Swiss residential energy system. It models the private household establishments's energy consumption and related technical investments. It is based on the Swiss MARKAL model which was recently taken over and further developed by researchers at the Paul Scherrer Institute where it has been used, among other, to analyze the Swiss 2000W society initiative [26]. The MARKAL-CHRES is a subset of the complete Swiss model. It is restricted to technologies related to the residential sector and considers final energies as being imported with exogenous prices. The model contains 173 technologies using different energies sources, i.e., coal, oil, gas, electricity, wood, pellets, and district heat.

The model base year (2000) is calibrated to the International Energy Agency and Swiss General Energy statistics of the year 2000. The model has a time horizon of 50 years and is divided into 11 time periods each with a duration of 5 years except the base year (2000, 2001-2005, 2006-2010, ..., 2046-2050). The residential energy sector of the model includes 14 energy demand segments (see Table 1). The most important segments are the room-heating $(\mathrm{RH})$ segments which represent more than $70 \%$ of final energy demand. We distinguish four different demand categories for RH: single and multi family houses as well as existing and new buildings. In the model, we assume that dwellings constructed after the year 2000 are new buildings. The model uses $\mathrm{USD}_{2000}$ as currency; therefore, all monetary value are discounted to year 2000 values using a $5 \%$ discount rate.
Table 1 MARKAL-CHRES demand segments

\begin{tabular}{ll}
\hline RC1 & Cooling \\
RCD & Cloth drying \\
RCW & Cloth washing \\
RDW & Dish washing \\
REA & Other electric \\
RH1 & Room-heating SFH existing building \\
RH2 & Room-heating SFH new building \\
RH3 & Room-heating MFH existing buildings \\
RH4 & Room-heating MFH new buildings \\
RHW & Hot water \\
RK1 & Cooking \\
RL1 & Lighting \\
RRF & Refrigeration \\
\hline
\end{tabular}

SFH single-family houses, $M F H$ multi-family houses

One of the particularities of the MARKAL-CHRES model is to describe precisely a set of technologies which allow for energy savings in various processes. The idea behind those technologies is to take into account the reduction of energy demand which follows certain types of investment. For example, installing double windows increases insulation and therefore reduces heating demand. For a more detailed description of the technologies used in the MARKAL-CHRES model, see [25].

\section{Baseline}

We have taken into account the differences between the models to calibrate the baseline. First, whereas GEMINI-E3 annually simulates economic equilibrium from 2001 to 2050, MARKAL-CHRES minimizes the total discounted costs of 11 time periods between 2000 and 2050. Therefore, the MARKAL-CHRES data regarding the year 2000 have not been used for the coupling since GEMINI-E3 base year is 2001. Moreover, in order to obtain annual data from MARKAL-CHRES, we have used a linear interpolation. Secondly, we have made some assumptions and aligned the emissions between both models as explained below.

\subsection{Assumptions}

In order to perform a first coupling attempt, we have assumed that world energy prices are only slightly affected by changes in the energy use in Switzerland and are therefore kept fixed at the baseline levels in the MARKAL-CHRES. Moreover, the total households' consumption (energy and non-energy), which could be used as a proxy for the useful energy demands in the residential sector, does not greatly vary from the 
baseline to the counterfactual. Therefore, the useful energy demands in MARKAL-CHRES are kept constant.

Furthermore, in the MARKAL-CHRES model, population and economic estimates (e.g., GDP) together with construction estimations are used in order to estimate the reference energy area (REA), i.e., the total useful surface of all heated rooms. The heating demands or useful energy used for heating (terajoules per year) is equal to the specific room heating demand (megajoules per square meter per year) multiplied by REA (Mio square meter). The Swiss Federal Office of Energy provides estimates of the REA until 2035. Values until 2050 are extrapolated.

In GEMINI-E3, population assumptions are based on the United Nations' medium scenario. The Swiss population is expected to grow until 2030 at a level of approximately 7.4 million people and then slowly decrease to reach 7.25 in 2050. Finally, according to the projections by [27], the annual average GDP growth rate is expected to be $1.2 \%$ from 2001 to 2020 and $0.6 \%$ from 2020 to 2050 . We also use the projections from [7] for oil, gas, and coal prices.

This study does not take into account that, in relatively cold country such as Switzerland, global warming could have some positive impacts in the demand for heating. Indeed, [5] find that the impact of climate change on residential heating at the end of the century could be a significant. They find that the decrease of heating degree days could reach $13-87 \%$, depending on the location and the strengthening of global warming. However, they also point out that the demand for space cooling will increase. In the Swiss energy outlook
[12] published by the Swiss Federal Office of Energy, the impact of global warming would be a decrease of household energy demand for heating by $4-6 \%$ in 2035 and an increase of household electricity demand for cooling by $3-5 \%$.

\subsection{Emissions}

We import the fuel mix from MARKAL-CHRES into GEMINI-E3 in order to align the emissions in the residential sector between the two models. The annual variation of the total energy consumption in GEMINIE3 Swiss residential sector is aligned to the variation of the total use of energy in MARKAL-CHRES. Moreover, the shares between the different energies are defined using the fuel mix (see Section 4 for details). Furthermore, we set the growth of technical progress in the private transport energy nest and of general technical progress in the use of fossil fuels to $1.25 \%$ in order to have the total $\mathrm{CO}_{2}$ emissions baseline decline by $13 \%$ between 2000 and 2035 as forecasted by [28]. Figure 2 shows the baseline $\mathrm{CO}_{2}$ and other GHG emissions calculated by GEMINI-E3 using the fuel mix from MARKAL-CHRES. Emissions of other $\mathrm{GHG}$ are transformed into $\mathrm{CO}_{2}$ equivalent $\left(\mathrm{CO}_{2}\right.$ eq) for comparison and summing requirements. They represent the amount of $\mathrm{CO}_{2}$ that would have the same global warming potential, when measured over a specified timescale. The natural decline of emissions is partly due to the availability of costless abatement measures, but also to the existing energy
Fig. 2 Baseline $\mathrm{CO}_{2}$ and GHG emissions

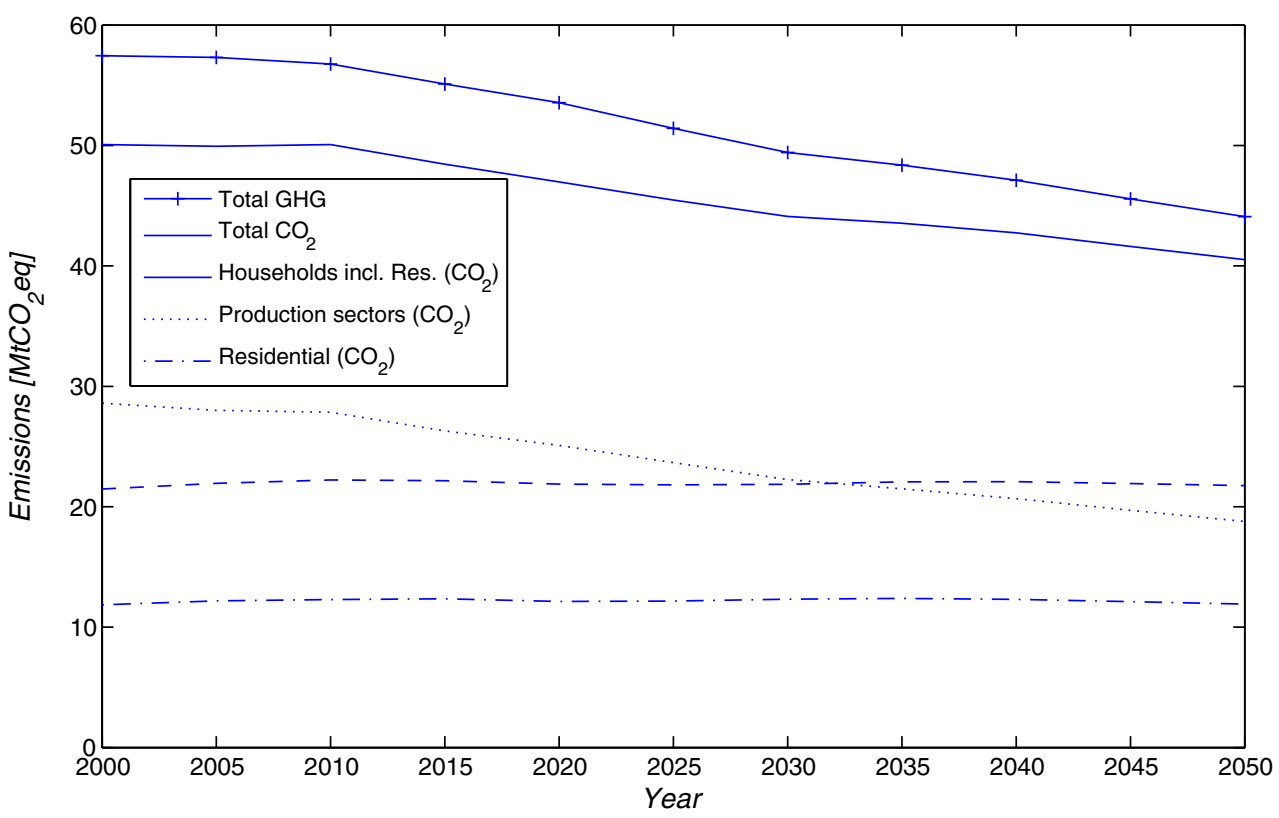


and climate policy instruments (e.g., R\&D, fuel taxes, regulations).

\section{Coupling}

GEMINI-E3 and MARKAL models are complementary for two reasons. First, CGE models allow for an explicit representation of the economy and are based on sound micro-economic foundations. Nevertheless, even with a rich disaggregate formulation, they generally fail to depict precisely the evolution of substitution among technologies as well as the energy use and do not respect the physical energy conservation principles. In that respect, bottom-up models perform much better. In contrast, because they focus mainly on rich technology representation and cost minimization objectives, thus they fail to represent the complex market interactions which are dealt with by CGE models. Secondly, recursive dynamic CGE models, such as GEMINIE3, have a myopic behavior, i.e., simulating one period at the time. Conversely, bottom-up models of the MARKAL family are perfect information perfect foresight model and minimize the costs of the system across the whole time frame. Hence, using MARKALCHRES to asses the evolution of the energy use in the residential sector of GEMINI-E3 allows for introducing some anticipations into GEMINI-E3. This is particularly useful when considering taxes which value is known to increase progressively over time.

Different from [8], where the residential energy consumption is subtracted from total consumption in order to calculate $\mathrm{CO}_{2}$ emissions from the rest of the economy, we have used the MARKAL-CHRES fuel mixes in GEMINI-E3 residential nest to calculate $\mathrm{CO}_{2}$ and other GHG emissions together with all other macroeconomic variables. In order to do so, the share parameters in the residential energy nest $\left(\alpha_{i \text { CHE }}^{\text {resee }}\right)$ (see Eq. 4 in "Appendix") are defined using the values calculated by the MARKAL-CHRES and the elasticity $\sigma_{\mathrm{CHE}}^{\text {hrese }}$ is set to 0 . In other words, we use a Leontief formulation in the residential energy nest. When relative fuel prices change, following the introduction of a tax, the substitutions between the various energies in the residential sector is therefore computed by MARKALCHRES. Furthermore, the variation of total residential energy (HCRESE) between the baseline and the counterfactual is fixed, imposing the same variation as the one of the sum of the fuel mixes. This new approach is made possible by the introduction of a CES utility function that replaces the Stone-Geary function used in previous versions of GEMINI-E3. In this first coupling attempt using a CES utility function and sim- ilarly to what has be done in [8], we do not link the capital investments simulated in MARKAL-CHRES and the equivalent consumption (residential—other) in GEMINI-E3.

\subsection{Coupling Method}

In this paper, we use a simple dichotomic procedure, which is sufficient in the case of a single control variable. In our case, the variable will represent the $\mathrm{CO}_{2}$ or GHG taxes. Indeed, in our coupled model, emissions in the target year are monotonic decreasing with respect to the tax. This ensures that our simple coupling module finds the unique optimal tax for each abatement target.

The coupling module functions as follows: We first initialize the minimum and maximum bounds for the $\operatorname{tax}\left(t_{\min }\right.$ and $\left.t_{\max }\right)$, the tax level ( $\left.\operatorname{tax}\right)$, the emission target $(\bar{e})$, and the initial emissions calculated by GEMINIE3 $(e=G(\operatorname{tax}, \mathrm{fm}), G(\operatorname{tax}, \mathrm{fm})$ being a run of the GEMINI-E3 model with a fixed tax and fuel mix fm). We run MARKAL-CHRES to calculate the fuel mix $(\mathrm{fm}=M(\operatorname{tax}), M(\operatorname{tax})$ being a run of the MARKALCHRES model with a fixed tax) and then GEMINI-E3 to calculate the total emissions in the target year $(e=$ $G(\operatorname{tax}, \mathrm{fm}))$ as long as the difference between emissions in the target year and the emission target is greater than a defined threshold $(|e-\bar{e}|>0.01)$ and the tax variation between two runs is greater than another threshold $\left(\left|\operatorname{tax}_{-1}-\operatorname{tax}\right|>0.01\right)$. If the total emissions are lower than the target, we redefine the upper bound of the tax $\left(t_{\max }=\operatorname{tax}\right)$; otherwise, we redefine the lower bound $\left(t_{\min }=\operatorname{tax}\right)$. We store the tax level for future comparisons $\left(\operatorname{tax}_{-1}=\operatorname{tax}\right)$ and define the new $\operatorname{tax}\left(\operatorname{tax}=t_{\min }+\right.$ $\left.\left(t_{\max }-t_{\min }\right) / 2\right)$.

The variable $\mathrm{fm}$ is the fuel mix matrix in the residential sector calculated by MARKAL-CHRES and is defined as follows:

$\mathrm{fm}=\left(\begin{array}{cccc}\mathrm{fm}_{\text {coal }, 2000} & \mathrm{fm}_{\text {coal }, 2005} & \cdots & \mathrm{fm}_{\text {coal }, 2050} \\ \mathrm{fm}_{\mathrm{gas}, 2000} & \mathrm{fm}_{\mathrm{gas}, 2005} & \cdots & \mathrm{fm}_{\text {gas }, 2050} \\ \mathrm{fm}_{\text {petr,2000 }} & \mathrm{fm}_{\text {petr, 2005 }} & \cdots & \mathrm{fm}_{\text {petr }, 2050} \\ \mathrm{fm}_{\text {elec, } 2000} & \mathrm{fm}_{\text {elec }, 2005} & \cdots & \mathrm{fm}_{\text {elec }, 2050}\end{array}\right)$,

where $\mathrm{fm}_{\text {coal }, t}, \mathrm{fm}_{\text {gas }, t}, \mathrm{fm}_{\text {petr }, t}$, and $\mathrm{fm}_{\text {elec }, t}$ are, respectively, the energy consumptions of coal, gas, petroleum products, and electricity in the year $t$.

Figure 3 presents this coupling schema. The tax is the variable that allows to control both models, the residential fuel mix is the coupling variable ensuring that GEMINI-E3 calculates emissions on the basis of the MARKAL-CHRES simulations, and the total emissions in the target year are the optimization variable ensuring that the coupled models converge to the target defined by policymakers. 
Fig. 3 Coupling structure

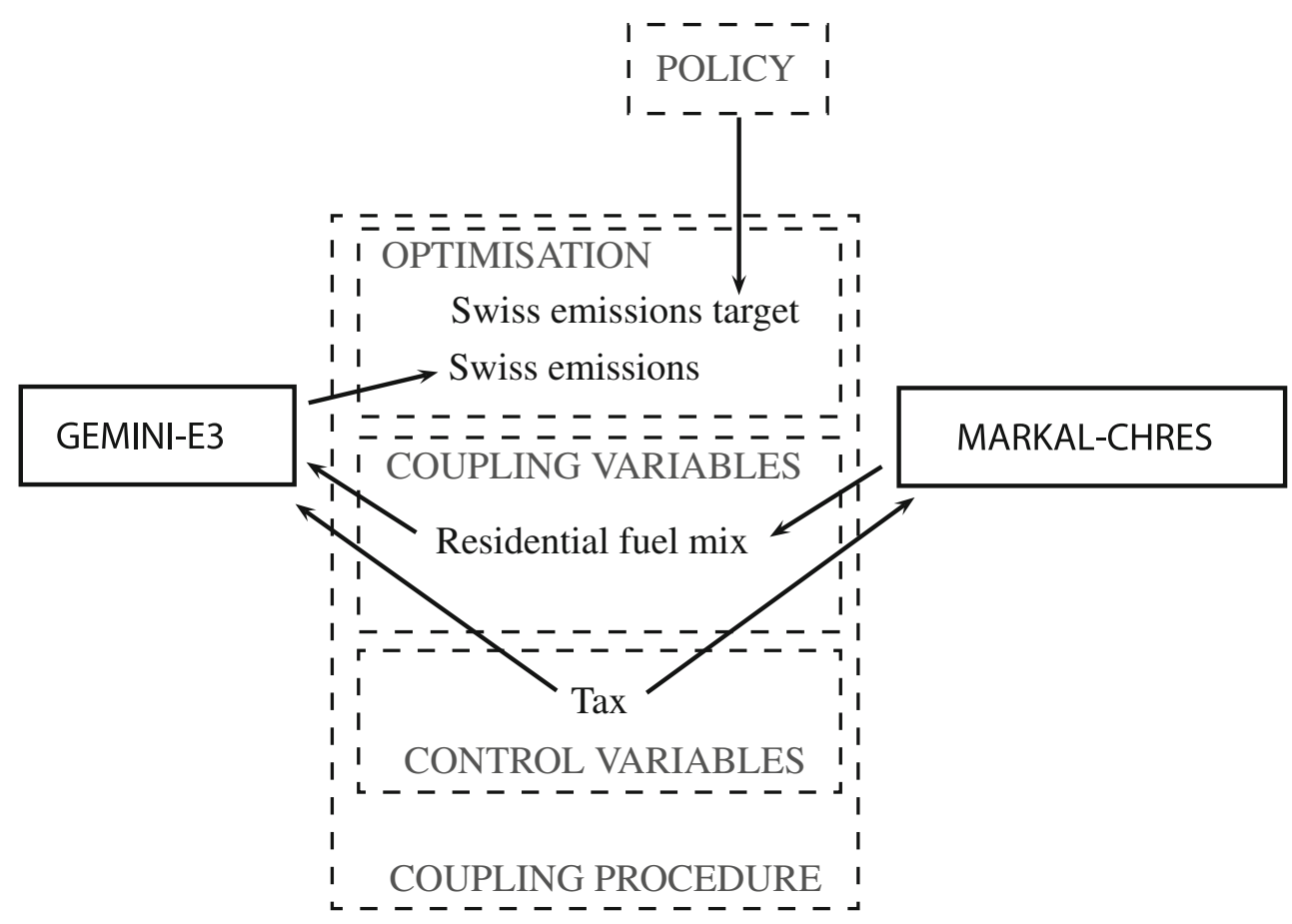

\subsection{Sensitivity Analysis of the Coupled Model}

Figure 4 shows the sensitivity of the model to various levels of taxation. The lines represent taxes of 0 (plain), 50 (dash-dot), 100 (plus), 150 (star), and $200 \mathrm{USD} / \mathrm{tCO}_{2}$ eq (circles); colors are used to differentiate between the various types of emissions (see legend). The figure shows that both the total $\mathrm{CO}_{2}$ and total GHG emission decline strongly when the progressive tax is set up to reach $150 \mathrm{USD} / \mathrm{tCO}_{2}$ eq by 2050. With such taxation levels, the residential sector, which presents high substitution potentials in this coupled framework, exhausts all its abatement potential as early as 2035 . The figure also demonstrates that private
Fig. 4 Impact on $\mathrm{CO}_{2}$ and GHG emissions of various levels of progressive taxes $(0,50,100,150$, and $200 \mathrm{USD} / \mathrm{tCO}_{2}$ eq)

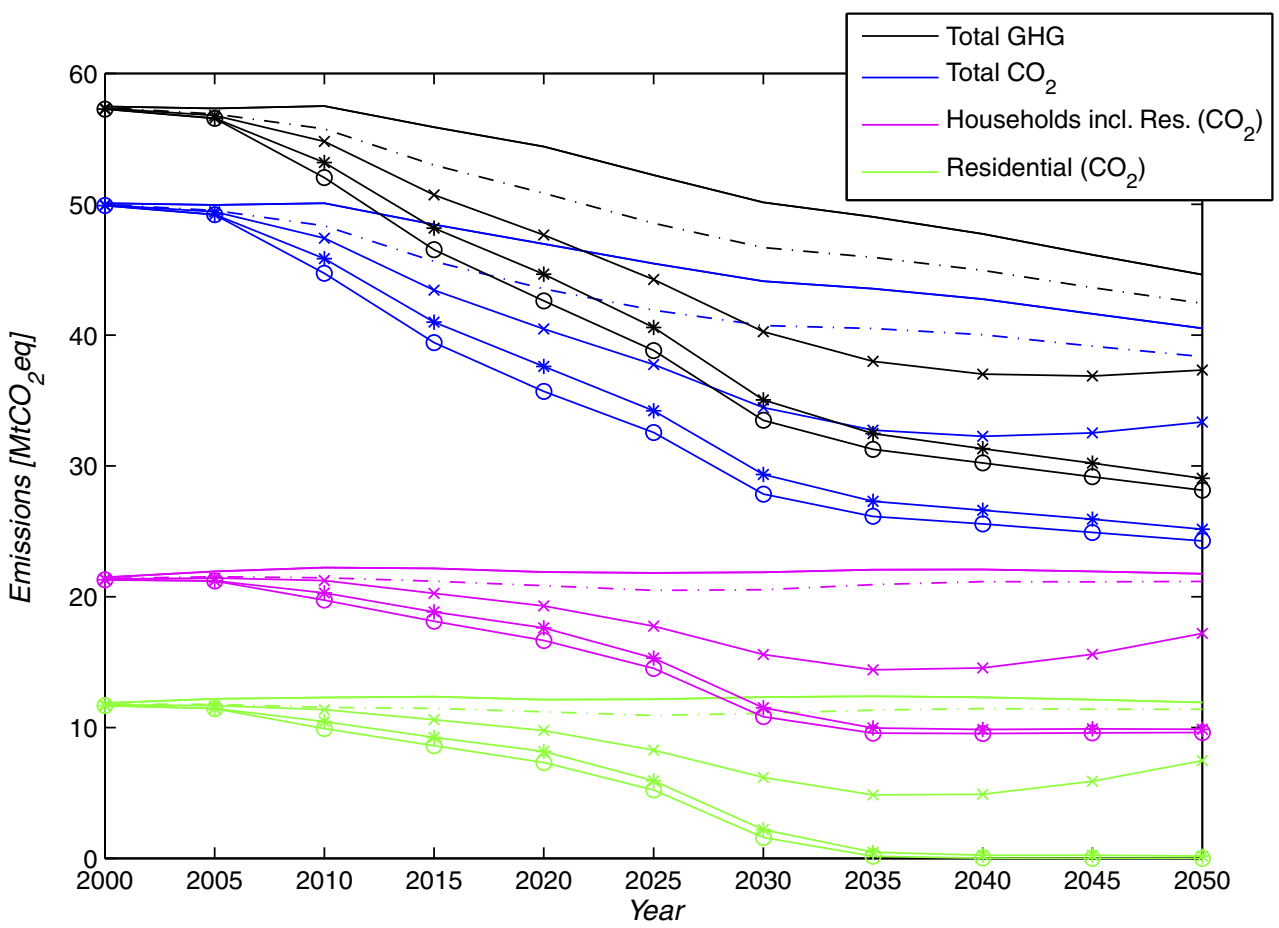



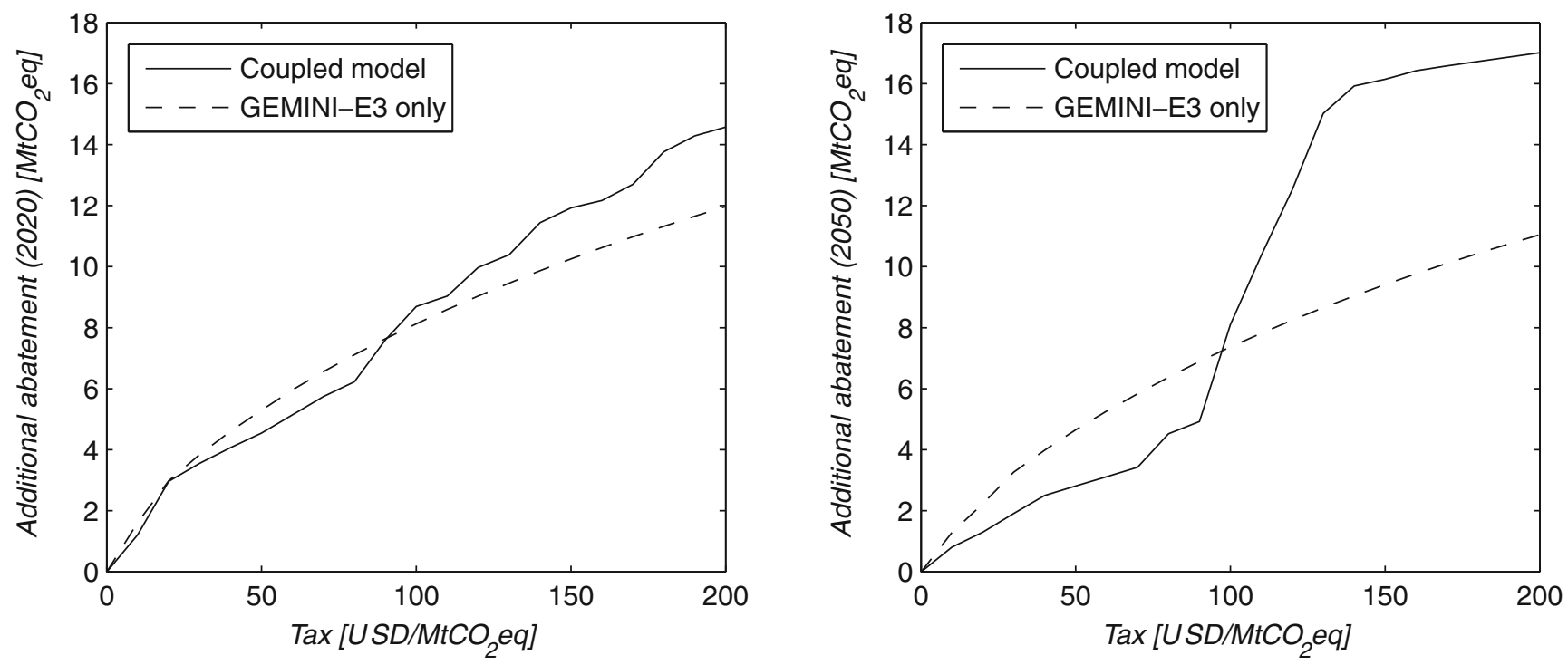

Fig. 5 Comparison of GEMINI-E3 with the coupled model—additional total abatement in 2020 (left) and 2050 (right)

transportation, the other part of households' emission, is quite inelastic. This is a consequence of having only petroleum products as source of energy for households private transportation as well as having incorporated the existing differentiation in the taxation of petroleum products according to their use. The $\mathrm{CO}_{2}$ tax affects more the relative prices of heating oil than those of gasoline or diesel.

Figure 5 shows the additional abatement in 2020 and 2050 at various levels of tax for both the original GEMINI-E3 and the coupled model. It is interesting to notice that a pure CGE model like GEMINI-E3 allows for stronger abatement than the coupled model when it comes to relatively small taxes. Nevertheless, it is not able to model the substitution to future efficient but expensive technologies when taxes are over $100 \mathrm{USD} / \mathrm{tCO}_{2}$ eq. Therefore, only the coupled model enables us to reach the high levels of abatement we are expecting in 2050 with realistic taxation levels. We observe in Fig. 4 that the abatement possibilities in the residential sector tend to be exhausted quickly when the tax level reaches $150 \mathrm{USD} / \mathrm{tCO}_{2}$ eq. As a consequence, in 2050, the total additional abatement tends to stabilize after having reached $16 \mathrm{MtCO}_{2}$ eq.

\section{Policy Scenarios}

In 2007, the Swiss Federal Council had decided that Swiss energy policy would be based on four pillars: the increase of energy efficiency, the promotion of renewable energy, the replacement and construction of electric power plants, and international energy policy.
These four pillars will support the climate policy targets, and they should also support action plans aiming at a reduction of the use of fossil fuels by $20 \%$ by 2020 , an increase of $50 \%$ in the use of renewable energy by the same year, and a limit of $5 \%$ on the growth of electricity consumption between 2010 and 2020 .

In December 2008, the Swiss Federal Council launched a 3-month consultation on two variants for revising the existing $\mathrm{CO}_{2}$ law after it expires in 2012:

1. The same reduction targets as the European Union, i.e., $20 \%$ reductions of $\mathrm{GHG}$ emissions relative to 1990 by 2020 and $50 \%$ by 2050 ; a pure incentive tax on all fossil fuels would be set to meet those targets, i.e., it would be responsive to economic growth, fossil fuel prices, and the effects of other energy conservation and substitution measures; the revenues of the tax could be redistributed to households and firms or used to subsidize energy conservation measures; firms that reduce their emissions by as much as under the tax would get it refunded; they may purchase compensation abroad so long at it does not exceed one fourth of total reductions.

2. A $50 \%$ reduction target for 2020 and full climate neutrality after 2030 , provided the international community agrees on an ambitious climate regime; $17.8 \%$ of the reduction would be obtained by energy conservation and substitution measures, without specific tax; $32.2 \%$ would be obtained through the purchase of emissions certificates on world markets by the importers of fossil fuels; in order to make sure that they purchase the certificates, they would have to pay into a guarantee fund 
$36 \mathrm{CHF} / \mathrm{tCO}_{2}$ (21 USD 2000 ), which they would recover when they prove the compensation of $50 \%$ of the imported $\mathrm{CO}_{2}$; this puts a ceiling of $42 \mathrm{USD}_{2000}$ on the price fossil fuel importers would pay for emissions certificates; if world prices exceed that ceiling, there would be no compensation and the target would be missed.

In this paper, we do not simulate exactly these policies but rather more stylized scenarios and focus on variant 1 . In order to facilitate the transition between the current $\mathrm{CO}_{2}$ Law, which targets only $\mathrm{CO}_{2}$ emissions, and the future policies which will encompass all GHGs, we have decided to consider objectives for both $\mathrm{CO}_{2}$ and all GHG emissions. Among the policy instrument and measures under consideration, we have selected those which either focus on the residential sector or have a wide impact on the economy. As a consequence, we have decided to analyze pure incentive GHG and $\mathrm{CO}_{2}$ taxes as well as technical regulations enforced in the residential sector. We study the potential abatement and the consequences following the implementation of both instruments separately as well as jointly. In this study, the tax revenues of the so-called pure incentive taxes are redistributed to households through lump sum transfers. Further studies could analyze the influence of various redistribution schemas or specific uses of the tax revenue.

We test three different scenarios. In the first scenario, we implement emission taxes applied across the whole Swiss economy, influencing both the production sectors and the households by changes in relative prices. We analyze two type of taxes, first a progressive tax that increases linearly up to the target year and, secondly, a uniform tax, which has a fixed value from 2008 till 2050. We also compare $\mathrm{CO}_{2}$ taxes with taxes covering all GHG.

The second scenario focuses on measures restricted to the residential sector and is not designed to achieve a specific abatement; therefore, it cannot be compared to the first scenario. In the second scenario, we consider the implementation of technical regulations which aims at restricting the residential investments in technologies considered inefficient as of 2015. In order to define the inefficient technologies, we compare the energy efficiency of each technology with the average efficiency of the technologies allowing for satisfying the same final energy demand (see Table 1). The technologies having an energy efficiency below the average are considered inefficient. Then, as of 2015, we exclude households' investments in inefficient technologies. Technologies not using fossil fuels or electricity are not restricted, and in the case of residential heating, we do not consider heat pumps, neither in the calculation of the average efficiency nor in the list of restricted technologies given their high energy efficiency. Examples of inefficient technologies falling in the restricted list are incandescent and halogen lamps.

Finally, the third scenario considers the joint use of both instruments, trying to mimic the potential implementation of a portfolio of measures that have different fields of application. The next section presents the integrated assessment of our scenarios.

\section{Results}

In this section, we present the results of the scenarios described above from the perspective of their environmental effectiveness (i.e., emissions reduction) as well as their consequences on the Swiss economy and on the residential sector in particular.

\subsection{Pure Incentive Tax}

The results in Table 2 show that a $20 \%$ reduction of GHG emissions by 2020 requires a $97.9 \mathrm{USD} / \mathrm{tCO}_{2} \mathrm{eq}$ progressive tax on all GHG and the tax should reach 201.6 USD/tCO 2 eq to allow a $50 \%$ abatement by 2050 . The level of those taxes could obviously be reduced if the taxes were set uniformly across periods. Furthermore, when only $\mathrm{CO}_{2}$ emissions are taxed, similar abatement levels require higher taxation levels, which could go up to almost $220 \mathrm{USD} / \mathrm{tCO}_{2}$ eq to abate GHG emissions by $50 \%$ in 2050 . These results confirm that without emissions trading, achieving substantial abatement levels in Switzerland requires a significant level of taxation. In comparison, these levels of taxation are much higher than the $\mathrm{CO}_{2}$ tax introduced in 2008 on heating and process fuels, which amounts to $12 \mathrm{CHF} / \mathrm{tCO}_{2}$ and should grow to $36 \mathrm{CHF} / \mathrm{tCO}_{2}$ in 2010.

In the case of a $50 \%$ abatement target, the model faces rigidities in private transportation where little substitution is possible even with distant horizons such as 2050. Modeling the transportation sector using an

Table 2 Abatement and pure incentive taxes in $\mathrm{USD} / \mathrm{tCO}_{2}$ eq

\begin{tabular}{lccccc}
\hline & $\mathrm{CO}_{2}$ tax & & & GHG tax & \\
\cline { 2 - 3 } Target & Progressive & Uniform & & Progressive & Uniform \\
\hline $20 \%$ by 2020 & 105 & 93 & & 98 & 89 \\
\% in 2050 & 37 & 29 & & 35 & 32 \\
$50 \%$ by 2050 & 220 & 157 & & 202 & 134 \\
\% in 2020 & 18 & 27 & & 17 & 25 \\
\hline
\end{tabular}


energy use model would allow for a better representation of the substitution possibilities and therefore would allow reaching similar targets with lower taxes. The figures in italic, the intermediate (2020) or final (2050) abatement levels associated with the taxes, show that the taxation levels set out to reach the 2020 target would not allow to reach the 2050 objectives. Similarly, taxes allowing to reach the 2050 targets are either insufficient, if implemented in a progressive way, or too restrictive, when implemented uniformly across the whole period. If both the 2020 and 2050 objectives need to be met, the tax could be implemented progressively but not linearly. In that case, the annual increase in the first phase (before 2020) should be stronger than in the second phase.

\subsection{Technical Regulations}

We find that the use of technical regulations, as we have define them, has a limited impact on Swiss $\mathrm{CO}_{2}$ and GHG emission. Figure 6 compares the baseline emissions with (lower line) and without (upper line) technical regulations in the residential sector. The impact of the technical regulations is slightly more important on $\mathrm{CO}_{2}$ emissions than on total GHG emissions due to the targeting of the regulations on $\mathrm{CO}_{2}$ intensive technologies. The maximum impact of the regulation is of about $2 \%$ around 2020 .

The reason for this limited effect on GHG emissions of the technical regulations as we have defined them partly lies in the definition itself. Indeed, the regulation does not take into account the energy efficiency of heat pumps when calculating the average energy efficiency of the technologies providing for room heating. Therefore, and in view of high investment costs required for technologies providing alternatives to oil burners, room heating remains a major consumer of light fuel oil despite the technical regulations. Including heat pumps into the calculation of the average efficiency for room heating would further trigger a switch toward $\mathrm{CO}_{2}$-free technologies.

Other measures than those we have modeled could have a greater impact on emissions and would deserve further consideration. Among those, we can mention: financing a program promoting the energetic renovation of buildings, implementing technical regulations on vehicles, strengthening research on energy efficiency, or accelerating technological transfer.

\subsection{Joint Use of Technical Regulations and Taxes}

When the coupled model takes into account the implementation of the technical regulations, the $\mathrm{CO}_{2}$ and GHG taxes allowing for achieving the abatement target are not significantly different from those calculated without technical regulations. This is mainly due to the fact that the less efficient technologies are naturally abandoned by households since $\mathrm{CO}_{2}$ or GHG taxes further reduce their competitiveness. Nevertheless, despite their little effect on $\mathrm{CO}_{2}$ emissions abatement, technical regulations are worth to be considered. Our results show that, when combined with taxes, they
Fig. 6 Impact of the technical regulations on the baseline $\mathrm{CO}_{2}$ and $\mathrm{GHG}$ emissions

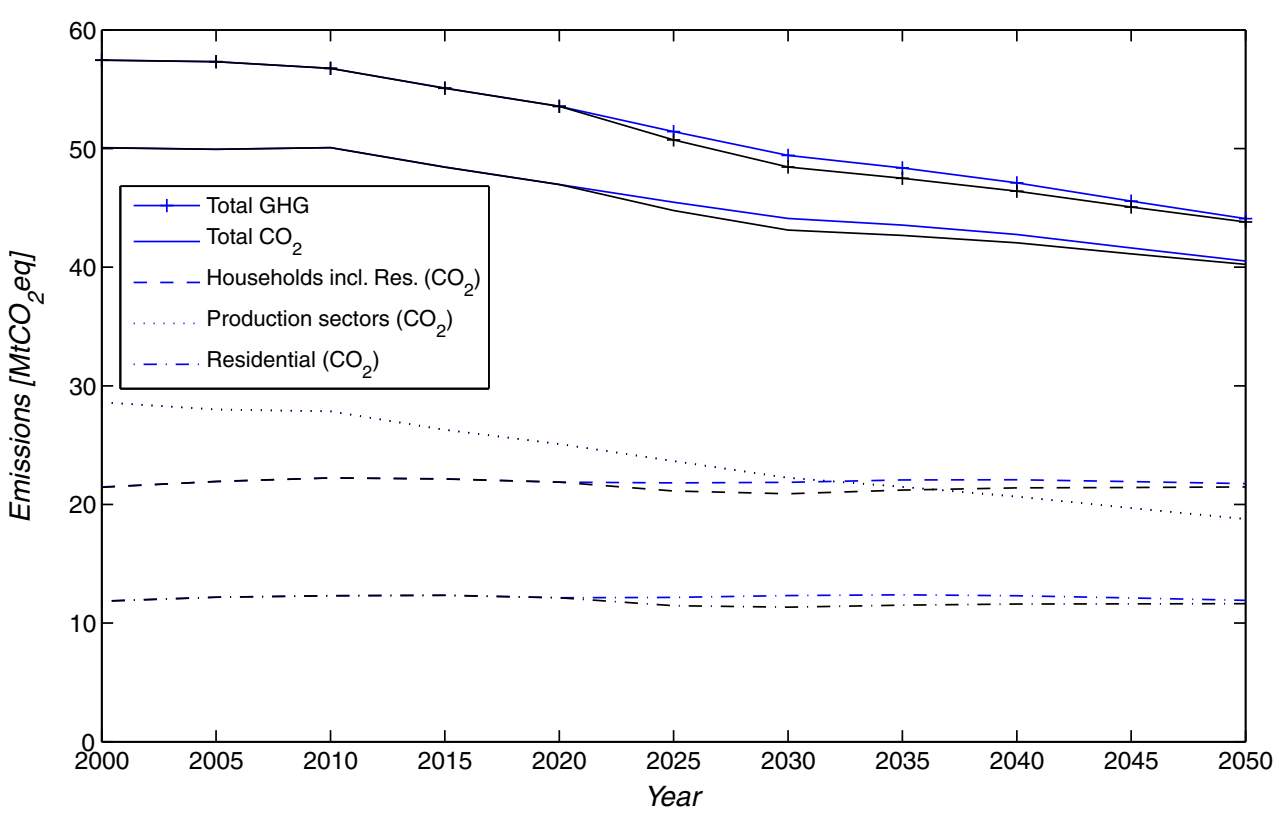


Table 3 GDP variations without technical regulations (in percent)

\begin{tabular}{lllll}
\hline Gas & Target & Tax & 2020 & 2050 \\
\hline GHG & $20 \%$ by 2020 & Progressive & -0.17 & -0.21 \\
& & Uniform & -0.16 & -0.17 \\
& \multirow{2}{*}{$50 \%$ by 2050} & Progressive & -0.11 & -0.41 \\
& & Uniform & -0.24 & -0.36 \\
& \multirow{2}{*}{$20 \%$ by 2020} & Progressive & -0.19 & -0.26 \\
& & Uniform & -0.17 & -0.18 \\
& \multirow{2}{*}{$50 \%$ by 2050} & Progressive & -0.12 & -0.44 \\
& & Uniform & -0.28 & -0.39 \\
\hline
\end{tabular}

provide a way to limit the increase of electricity consumption which is also on of the target of the future revision of the Swiss $\mathrm{CO}_{2}$ Law. In view of the limited abatement obtained by the implementation of technical regulations, we concentrate the rest of the analysis on the first scenario.

\subsection{Impacts on the Swiss Economy}

Table 3 shows the variations of GDP due to the pure incentive taxes defined in Table 2 for the years 2020 and 2050. The figures show that the impact of emission taxes on the Swiss economy is limited and, in all cases, would reduce GDP by less than half a percent compared to the baseline, even with taxes as high as $200 \mathrm{USD} / \mathrm{tCO}_{2}$ eq. Moreover, GHG taxes have a smaller impact on GDP than $\mathrm{CO}_{2}$ taxes. The effects on GDP might be a little stronger if we forced the CGE part of the model to mimic the increased spending on equipment suggested by the MARKAL-CHRES. Indeed, the tax has an inci- dence on consumers' investment strategies, i.e., they invest in less polluting but more expensive technologies. When technical regulations are combined with taxes, we observe the same impacts on GDP.

In our assessment, only uniform taxes set to meet the 2050 targets allow to meet both 2020 and 2050 targets. Nevertheless, progressive taxes have a higher chance to be accepted since their total cumulated impact on GDP from 2008 to 2050 is smaller. Figure 7 shows the impacts on the production sectors of a $219.7 \mathrm{USD} / \mathrm{tCO}_{2}$ tax on $\mathrm{CO}_{2}$ and a $201.6 \mathrm{USD} / \mathrm{tCO}_{2}$ eq tax on all GHGs. The only sector that strongly benefits from the introduction of the taxes is the electricity sector, due to the increased demand for electricity which is produced mainly $\mathrm{CO}_{2}$ free in Switzerland. In the case that current nuclear power plants were replaced by combined cycle gas turbines, emission taxes would have to be higher and the electricity sector would not benefit as much from the introduction of the tax. The petroleum products sector is the most affected by the introduction of the taxes, together with other energy intensive sectors such as mineral products, agriculture, and air transport. Not surprisingly, in our modeling framework, other transport (transport nec), which includes commercial road transport and rail, is not that much affected by the tax in view of the substitution between private and purchased transport.

Table 4 presents the contributions of households and economic sectors to $\mathrm{CO}_{2}$ abatement as well as the contributions of the different greenhouse gases to total abatement. The major contribution to the $\mathrm{CO}_{2}$ abatement effort is attributed to households with a
Fig. 7 Variation of production in 2050 relative to baseline

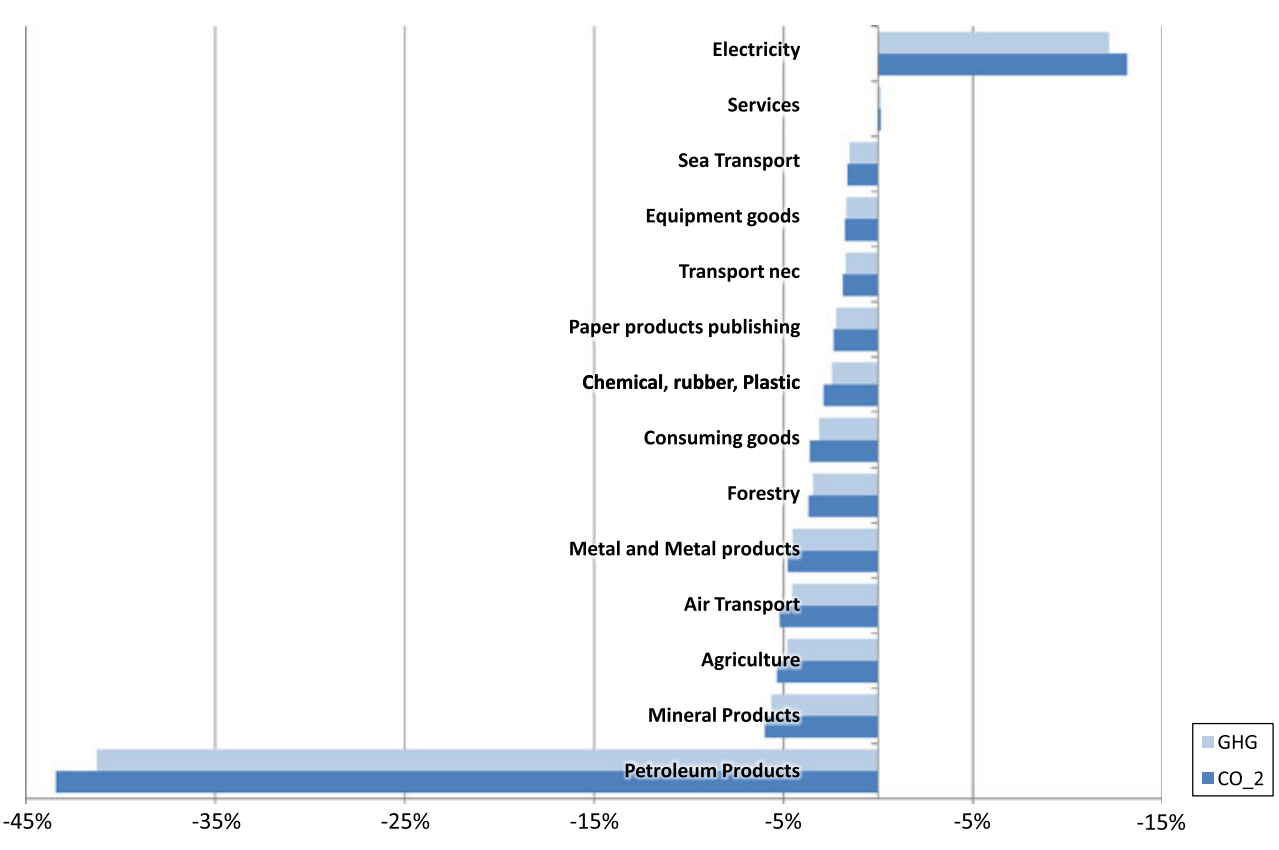


Table 4 Contributions to the change in emissions between 2000 and 2050 after progressive taxation

\begin{tabular}{lrr}
\hline Sectors/gases & GHG tax & $\mathrm{CO}_{2}$ tax \\
\hline Households & 35.11 & 37.78 \\
Transport nec & 16.55 & 16.86 \\
Services & 8.64 & 8.92 \\
Air transport & 4.90 & 5.06 \\
Mineral products & 4.25 & 4.29 \\
Consuming goods & 3.25 & 3.29 \\
Equipment goods & 2.13 & 2.16 \\
Petroleum products & 2.09 & 2.13 \\
Paper products publishing & 1.91 & 1.93 \\
Metal and metal products & 1.86 & 1.87 \\
Agriculture & 1.09 & 1.10 \\
Chemical, rubber, plastic & 0.99 & 1.01 \\
Electricity & 0.92 & 0.93 \\
Forestry & 0.34 & 0.34 \\
Sea transport & -0.04 & -0.02 \\
$\mathrm{CO}_{2}$ & 83.97 & 87.66 \\
$\mathrm{CH}_{4}$ & 9.33 & 7.88 \\
$\mathrm{~N}_{2} \mathrm{O}$ & 7.25 & 6.62 \\
Fluorinated gases & -0.55 & -2.16 \\
\hline
\end{tabular}

share of $35 \%$, followed by road and rail transport which accounts for $16.5 \%$ of the emissions reductions between 2001 and 2050. If we consider that in the baseline scenario a certain level of abatement is already achieved as a consequence of currently adopted policies, the share of households in the additional abatement is as high as $74 \%$. All GHG contribute substantially to the overall abatement, in particular in the case of GHG taxation, with exception of fluorinated gases, which still increase despite the high levels of taxation. This occurs mainly because of an increase in $\mathrm{SF}_{6}$ (sulfur hexafluoride) emissions from electric power systems.
From an international perspective, we can confirm that Swiss policies, regardless of how stringent they are, have a very limited impact on the economies of the rest of the world, in particular when other regions are not undertaking GHG emissions abatement and no emission trading is envisaged. Nevertheless, the implementations of GHG and $\mathrm{CO}_{2}$ taxes in Switzerland influences the $\mathrm{CHF} / \mathrm{USD}$ exchange rate and, as a consequence, slightly affects trade flows. The Swiss exchange rate increases by $0.7 \%$ to $1.8 \%$ with respect to the US dollar depending on the level of the tax. Finally, the estimations confirm our initial assumption that the prices of energy would only vary slightly compared to the baseline due to the limited impact of Swiss energy demand on world prices.

\subsection{Impacts on the Residential Sector}

As we saw earlier, the implementation of emissions taxes has strong consequences on the residential sector. The bottom-up part of the coupled model shows, as presented in Fig. 8, that the residential sector reacts to the introduction of the taxes by a strong switch to electricity between 2020 and 2035. A uniform tax of 156.5 USD/tCO $\mathrm{tC}_{2}$ eq would even have an earlier and stronger impact and would even trigger an almost $\mathrm{CO}_{2}$ free residential sector.

Figure 9 presents the evolution of installed capacity of various room heating technologies following the implementation of a progressive GHG tax allowing to reach $50 \%$ abatement by 2050 . It clearly indicates that, in all building types, heat pumps will have a rapidly growing share and, as of 2030 , be the dominant technology used for room heating. This is due to the

Fig. 8 Residential fuel mix

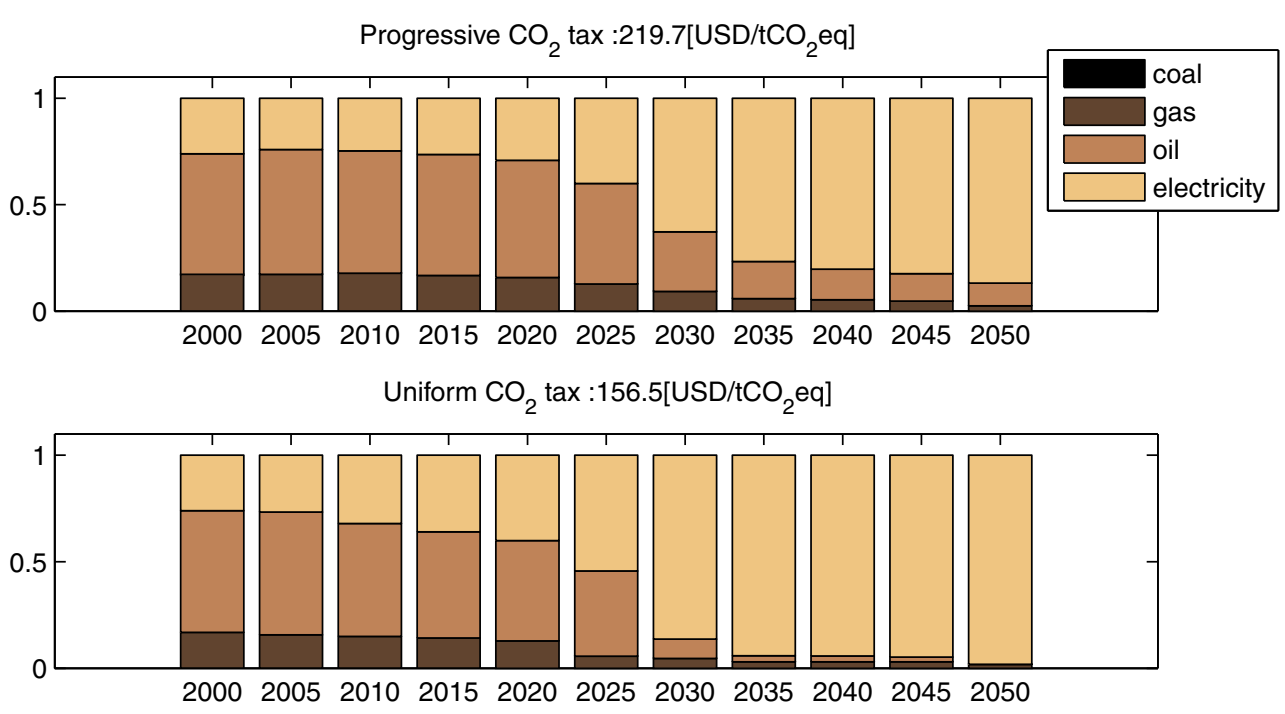



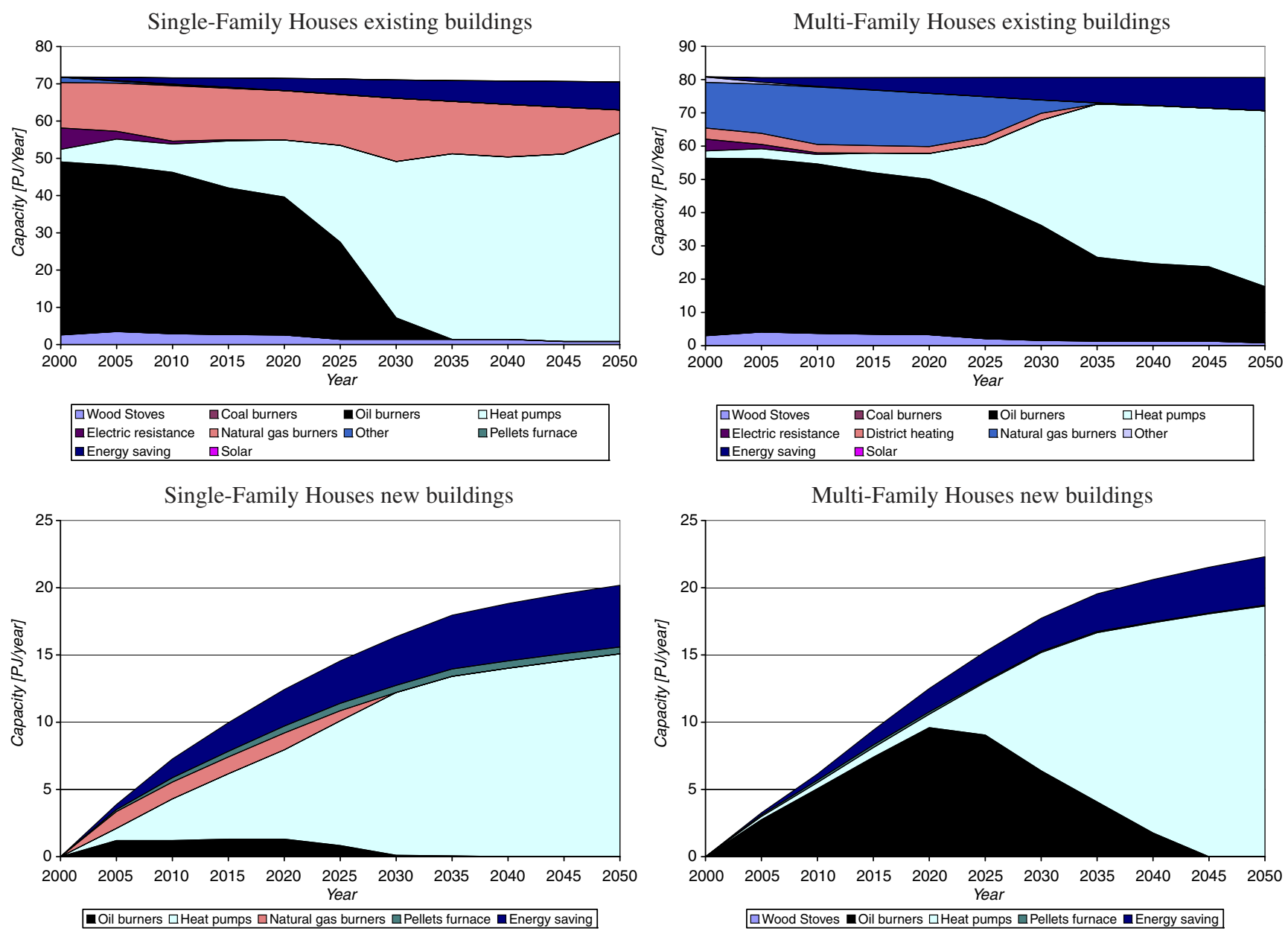

Fig. 9 Installed capacity of room heating technologies

fact that heat pumps have a high energy efficiency and that they only consume electricity, which is, to a large extent in Switzerland, not produced from fossil fuels. Finally, the figure also shows that an important part of the final energy demand is met by installing energy saving technologies, in particular in new single family houses where almost a fourth of the energy is saved by using appropriate insulation and other energy efficiency standards.

\section{Conclusions}

This paper provides a new integrated approach to analyzing GHG mitigation policies in Switzerland which provides useful insights relevant for the forthcoming revision of the $\mathrm{CO}_{2}$ Law and the elaboration of the post 2012 climate policies. We have focused this analysis on the residential sector which is expected to play a major role in future GHG abatement.
We have studied the impacts of $\mathrm{CO}_{2}$ and GHG taxes as well as technical regulation applied to the residential sector. We have shown that the latter would not be sufficient to achieve major emissions reductions and loose their raison d'être when used in conjunction with emission taxes. This effect might be a little overestimated by the MARKAL-CHRES part of the coupled model, which assumes that consumers adopt purely optimizing behavior which takes into account investment, maintenance, and usage prices of all technologies. Furthermore, this study confirms that GHG taxes are more effective than $\mathrm{CO}_{2}$ taxes, without further jeopardizing the production of the economic sectors. A progressive GHG tax reaching 201.6 USD/tCO $\mathrm{tC}_{2}$ eq in 2050 would yield a $50 \%$ reduction in GHG emissions relative to 1990 and would lower Swiss GDP by approximately $0.4 \%$ compared to the baseline. Such a tax would imply, for example, that the prices of light fuel oil used in the residential sector would increase annually by $0.012 \mathrm{USD}_{2000}$. 
Finally, this paper also shows that with high emissions taxes, private transportation becomes the principal emitter of GHG. This is in line with a recent proposal for a Swiss energy policy by [9], which states that emissions should be reduced to $1 \mathrm{tCO}_{2}$ per capita by 2100 , a sufficient condition to render the planet $\mathrm{CO}_{2}$ neutral if applied globally in a contraction and convergence framework, and that those emissions would only be restricted to the transportation sector. In the settings of this paper, the transportation sector remains a big emitter due to the rigidities in the model, which somehow reflects the lack of clean alternative technologies, but also to the fact that the price of petroleum products used for transport already includes high taxes and, therefore, the relative change in price is much lower than in the residential sector.

This research could be further developed by an analysis of the means that would allow for a $\mathrm{CO}_{2}$ neutral Switzerland, as well as their consequences. As assumed by the Federal Council, this could be done investing a part of the tax revenue in the purchase of foreign $\mathrm{CO}_{2}$ certificates. Having in mind that the marginal abatement costs in Switzerland are very high, the purchase of certificates would significantly lower the costs of abatement. Some amendments to our coupled model could enable a global or regional carbon market and, once abatement strategies in all regions would be defined, will allow the assessment of the price of $\mathrm{CO}_{2}$ certificates. Once climate policies will be internationally introduced in the models, energy prices and demands will vary substantially. Our coupling framework would therefore also need to be slightly amended to allow feedbacks from the top-down to the bottomup model. Furthermore, the variation of the investment costs following the implementation of the policies should be aligned between both models in order to render a more realistic framework with regard to the macroeconomic consequences of the investments in the residential sector. Finally, a more detailed modeling of the private transportation sector, possibly using another energy use model, would allow to take into account the realistic hypothesis that, before 2050, energies other that petroleum products could represent an important share in the private transportation fuel mix. These additional substitution potentials would allow for reaching the emission targets with lower taxes than those presented in this paper.

Acknowledgements This work has been undertaken with the support of the NSF-NCCR climate grant. We also would like to thank Professor Philippe Thalmann for his helpful comments as well as Dr. Kasten Nathani and Markus Wickart for providing us with a disaggregated 2001 Swiss input-output table.

\section{Appendix: Equations in the Residential Nest}

The residential part of the households consumption is calculated with the equations below where $r$ refers to regions and $t$ to the time period. $\lambda, \alpha$, and $\sigma$ are, respectively, the scale, share, and elasticity parameters of the CES functions.

The consumption of the residential aggregated good (HCRES) is calculated as:

$$
\begin{aligned}
\mathrm{HCRES}_{r} \cdot \theta_{r}^{\text {res } t}= & \mathrm{HCT}_{r} \cdot \lambda_{r}^{\mathrm{hct}} \cdot \alpha_{r}^{\mathrm{res}} \\
& \cdot\left[\frac{\mathrm{PCT}_{r}}{\mathrm{PCRES}_{r} \cdot \lambda_{r}^{\text {hct }} \cdot \theta_{r}^{\text {res } t}}\right]^{\sigma_{r}^{\mathrm{hc}}},
\end{aligned}
$$

where $\theta_{r}^{\text {res }}$ is the technical progress of the residential nest, HCT is the total aggregated consumption, PCT is the price of the aggregated consumption, and PCRES is the price of the residential aggregated good.

The consumption of the residential aggregated energy good (HCRESE) is calculated as:

$$
\begin{aligned}
& \operatorname{HCRESE}_{r} \cdot \theta_{r}^{\text {rese } t} \\
& =\mathrm{HCRES}_{r} \cdot \lambda_{r}^{\text {hcres }} \cdot \alpha_{r}^{\text {rese }} \\
& \quad \cdot\left[\frac{\mathrm{PCRES}_{r}}{\operatorname{PCRESE}_{r} \cdot \lambda_{r}^{\text {hcres }} \cdot \theta_{r}^{\text {rese } t}}\right]^{\sigma_{r}^{\text {hres }}},
\end{aligned}
$$

where $\theta_{r}^{\text {rese }}$ is the technical progress of the residential energy nest and PCRESE is the price of residential aggregated energy good.

The residential consumption of services $\left(\mathrm{HC}_{17, r}^{\mathrm{res}}\right)$ is calculated as:

$$
\begin{aligned}
\mathrm{HC}_{17, r}^{\mathrm{res}} \cdot \theta_{r}^{\text {res17t }}= & \mathrm{HCRES}_{r} \cdot \lambda_{r}^{\text {hcres }} \cdot\left(1-\alpha_{r}^{\text {rese }}\right) \\
& \cdot\left[\frac{\mathrm{PCRES}}{P C_{17 r} \cdot \lambda_{r}^{\text {hcres }} \cdot \theta_{r}^{\text {res17t }}}\right]^{\sigma_{r}^{\text {res }}},
\end{aligned}
$$

where $\theta_{r}^{\text {res17 }}$ is the technical progress of the residential consumption of services and $\mathrm{PC}_{17 r}$ is the price of the residential consumption of services.

The residential consumption of energies $\left(\mathrm{HC}_{i r}^{\mathrm{res}}\right)$ is calculated as:

$$
\begin{aligned}
\mathrm{HC}_{i r}^{\mathrm{res}}= & \mathrm{HCRESE}_{r} \cdot \lambda_{r}^{\text {hcrese }} \cdot \alpha_{i r}^{\text {resee }} \\
& \cdot\left[\frac{\mathrm{PCRESE}_{r}}{\mathrm{PC}_{i r} \cdot \lambda_{r}^{\mathrm{hcres}}}\right]^{\sigma_{r}^{\text {hrese }}}, \forall i=1, \ldots, 5,
\end{aligned}
$$

where $\mathrm{PC}_{i}$ the price of consumption goods $i$ and $\sum_{i} \alpha_{i r}^{\text {resee }}=1$.

Furthermore, the residential nest accounts for only a part of the consumption of energy goods as well as 
services. In order to have the total final consumption in those sectors, we use the following formulas:

$$
\begin{aligned}
& \mathrm{HC}_{i r}=\mathrm{HC}_{i r}^{\mathrm{res}}+\mathrm{HC}_{i r}^{\mathrm{tra}}, \forall i=1, \ldots, 5, \\
& \mathrm{HC}_{17 r}=\mathrm{HC}_{17 r}^{\mathrm{res}}+\mathrm{HC}_{17 r}^{\mathrm{oth}} .
\end{aligned}
$$

Finally, the prices of the aggregated goods (HCRES and HCRESE) are calculated as follows:

$$
\begin{aligned}
\operatorname{PCRES}_{r}=\lambda_{r}^{\text {res }} & {\left[\alpha_{r}^{\text {rese }} \cdot\left(\frac{\operatorname{PCRESE}_{r}}{\theta_{r}^{\text {rese } t}}\right)^{1-\sigma_{r}^{\text {res }}}\right.} \\
& \left.+\left(1-\alpha_{r}^{\text {rese }}\right) \cdot\left(\frac{\mathrm{PC}_{17 r}}{\theta_{r}^{\text {res } 17 t}}\right)^{1-\sigma_{r}^{\text {res }}}\right]^{\frac{1}{1-\sigma_{r}^{\text {res }}}},
\end{aligned}
$$

$\operatorname{PCRESE}_{r}=\lambda_{r}^{\text {rese }} \cdot\left[\sum_{i=1, \ldots, 5} \alpha_{i r}^{\text {resee }} \cdot \mathrm{PC}_{i r}^{1-\sigma_{r}^{\text {rese }}}\right]^{\frac{1}{1-\sigma_{r}^{\text {rese }}}}$

\section{References}

1. Bernard, A., \& Vielle, M. (1998). La structure du modèle GEMINI-E3. Economie et Prévision, 5(136), 19-32.

2. Bernard, A., \& Vielle, M. (2000). Comment allouer un coût global d'environnement entre pays: Permis négociables versus taxes ou permis négociables et taxes? Économie Internationale, 82, 103-135.

3. Bernard, A., \& Vielle, M. (2008). GEMINI-E3, a general equilibrium model of international-national interactions between economy, energy and the environment. Computational Management Science, 5(3), 173-206.

4. Böhringer, C. (1998). The synthesis of bottom-up and topdown in energy policy modeling. Energy Economics, 20, 233248.

5. Christenson, M., Manz, H., \& Gyalistras, D. (2006). Climate warming impact on degree-days and building energy demand in Switzerland. Energy Conversion and Management, 47, 671686.

6. Dimaranan, B. V. (Ed.) (2007). Global trade, assistance, and production: The GTAP 6 data base. West Lafayette: Center for Global Trade Analysis, Department of Agricultural Economics, Purdue University.

7. DOE (2006). International energy outlook. Washington, DC: DOE.

8. Drouet, L., Haurie, A., Labriet, M., Thalmann, P., \& Viguier, L. (2005). A coupled bottom-up/top-down model for GHG abatement scenarios in the housing sector of Switzerland. In R. Loulou, J.-P. Waaub, \& G. Zaccour (Eds.), Energy and environment (pp. 27-61). New York: Springer.

9. ETHZ (2008). Energy strategy for ETH Zurich.

10. Ferris, M. C., \& Munson, T. S. (2000). Complementarity problems in GAMS and the PATH solver. Journal of Economic Dynamics and Control, 24, 165-188.
11. Ferris, M. C., \& Pang, J. S. (1997). Complementarity and variational problems: State of the art. Philadelphia: SIAM.

12. Hofer, P. (2007). Der Energieverbrauch der Privaten Haushalte, 1990-2035: Ergebnisse der Szenarien I bis IV und der zugehrigen Sensitivitten BIP hoch, Preise hoch und Klima wrmer. Basel: Prognos AG.

13. IMF (2004). Government finance statistics. Washington, DC: IMF.

14. International Energy Agency (2002). Energy balances for non-OECD countries. Paris: OECD/IEA.

15. International Energy Agency (2002). Energy balances for OECD countries. Paris: OECD/IEA.

16. International Energy Agency (2005). Energy prices \& taxes. Paris: OECD/IEA.

17. Löschel, A., \& Soria, A. (2007). Impact of an increased use of renewable electricity: A quantitative assessment with a hybrid CGE model. In 9th IAEE European energy conference, Firenze.

18. Manne, A. S., \& Richels, R. G. (1992). Buying greenhouse insurance: The economic costs of $\mathrm{CO}_{2}$ emission limits. Cambridge: MIT.

19. Nathani, C., Wickart, M., Oleschak, R., \& van Nieuwkoop, R. (2006). Estimation of a Swiss input-output table for 2001. Technical report, ETH Zürich.

20. OECD (2003). Revenue statistics 1965-2002. Paris: OECD.

21. OECD (2005). National accounts for OECD countries. Paris: OECD.

22. Pizer, W., Burtraw, D., Harrington, W., Newell, R., Sanchirico, J., \& Toman, M. (2003). General and partial equilibrium modeling of sectoral policies to address climate change in the United States. Technical report, Resources for the future, Washington, D.C.

23. Sceia, A., Drouet, L., \& Vielle, M. (2007). Transformation of the 2001 Swiss SAM from ETH Zürich to GEMINI-E3 format. Mimeo.

24. Schäfer, A., \& Jacoby, H. (2006). Experiments with a hybrid CGE-MARKAL model. Energy Journal (Special issue: Hybrid modeling of energy-environment policies: Reconciling bottom-up and top-down), 171-177.

25. Schulz, T. F. (2007). Intermediate steps toward the 2000 Watt Society in Switzerland: An energy-economic scenario analysis. $\mathrm{Ph} . \mathrm{D}$. thesis, ETH Zürich.

26. Schulz, T. F., Kypreos, S., Barreto, L., \& Wokaun, A. (2008). Intermediate steps towards the $2000 \mathrm{~W}$ Society in Switzerland: An energy-economic scenario analysis. Energy Policy, 36(4), 1303-1317.

27. State Secretariat for Economic Affairs (2004). Ökonomisches Wachstum Schweiz-Zukunftszenarien.

28. Swiss Federal Office of Energy (2007). Perspectives énergétiques pour 2035 (tome 1) synthèse. Technical report, Département fédéral de l'environnement, des transports, de l'énergie et de la communication Office fédéral de l'énergie.

29. United States Environmental Protection Agency (2006). Global mitigation of non-CO2 greenhouse gases. Office of Atmospheric Programs (6207J) EPA 430-R-06-005, Washington, DC 20460.

30. Wing, I. (2006). The synthesis of bottom-up and top-down approaches to climate policy: Electric power technologies and the cost of limiting US $\mathrm{CO} 2$ emissions. Energy Policy, $34,3847-3869$. 